\title{
Inversion and Analysis of Land Surface Temperature based on Landsat - a case study of BeiBei District in Chongqing
}

\author{
Zhou Yang ${ }^{1}$, Liu Na-na ${ }^{1 *}$ \\ ${ }^{1}$ Chongqing Real Estate College, Chongqing 401331, China
}

\begin{abstract}
Land surface temperature is the surface of the earth's energy change and the exchange process, which is an important index for a lot of scientific research. In this paper, the surface temperature changes of BeiBei district in Chongqing in the past 20 years were inverted in 6 time phases. The surface temperature inversion method of Landsat remote sensing data was studied, and the atmospheric correction method was adopted to conduct the inversion by using Landsat5TM and landsat8OLI-TIRS image data. The results showed that from 2004 to 2014, the area of high temperature area increased year by year, and the area of low temperature area also increased year by year.
\end{abstract}

\section{Introduction}

Land surface temperature is the surface of the earth's energy change and the exchange process, it is the interaction between land and atmosphere comprehensive performance of energy conversion, which is a very important parameter on the study of regional and global scales on the surface of a physical system, and which is also an important index for many scientific research ${ }^{[1-3]}$. With the continuous development of remote sensing technology, the using of thermal infrared remote sensing data inversion of surface temperature becomes one of the most commonly used methods at present.

Taking BeiBei district of Chongqing as the research object, this paper used Landsat remote sensing image to invert the surface temperature of six phases from 2001 to 2017 and analyze them.

\section{Research area overview and data source}

\subsection{Research area overview}

Beibei district of Chongqing is located in east longitude $106^{\circ} 18^{\prime} 14^{\prime \prime}$ to $106^{\circ} 56^{\prime} 53^{\prime \prime}$, latitude $29^{\circ} 30^{\prime} 41^{\prime \prime}$ to $30^{\circ} 11^{\prime} 21^{\prime \prime}$, covering an area of $754.21 \mathrm{~km}^{2}$. Beibei district has a humid subtropical monsoon climate with abundant rainfall, characterized by early spring, hot summer, short autumn and late winter. The highest temperature is $44.3^{\circ} \mathrm{C}$. The minimum temperature is

$-3.1^{\circ} \mathrm{C}$, and the annual average temperature is $18.2^{\circ} \mathrm{C}$. Beibei district is a part of southwest col fold belt, Huaying mountain geji-block compound anticline arc structure area Chongqing arc. The basic topography of
BeiBei district is composed of the low mountain trough, the foothill naked hill, the shallow hill and the river valley. Within its scope the highest elevation is $1312 \mathrm{~m}$, the lowest elevation is $175 \mathrm{~m}$, so in the area of BeiBei mountains and hills are more, flat dam is less, but the water system is very rich. The whole region is a natural feature of "six hills, three mountains and one dam". Beibei district has the jurisdiction over Tiansheng Street, Chaoyang Street, Beiwenquan Street, Longfengqiao Street, Dongyang Street, Xiema Town, Jindaoxia Town, Sansheng Town, Shijialiang Town, Tongjiaxi Town, Caijiagang Town, Liuyin Town, Chengjiang Town, Jingguan Town, Fuxing Town, Shuitu Town, and Tianfu Town, and it has a permanent population of more than 800,000 .

\subsection{The data source}

This research uses the image data of Landsat5TM and Landsat8OLI-TITS, and the ranks number of Beibei district is $137 / 039$ and $137 / 040$. In order to better study the changes of surface temperature in BeiBei district over the past 20 years, according to the available images and the purpose of obtaining accurate inversion data, we try to select the image data with less cloud cover, good imaging quality and in the summer after analyzing all the image data, and finally we chose the images of six time phase years of 2001-2017, respectively in 2001, 2004, 2007, 2011, 2014 and 2017. Their imaging time is from May to September, because during this time, the temperature is higher.

\section{Land surface temperature inversion}

\footnotetext{
* Corresponding author: 545195968@qq.com
} 
There are three methods of surface temperature inversion using remote sensing images:atmospheric correction method (radiation transmission), split window algorithm, and multi-channel algorithm. Among them, atmospheric correction method is suitable for data sources of Landsat and TM/ETM+/TIRS series satellites. Combined with the image data selected in this study, surface temperature inversion using atmospheric correction method is adopted $^{[4-6]}$.

\subsection{TIRS inversion flow chart based on atmospheric correction method}

The thermal infrared radiation luminance value $\mathrm{L}_{\lambda}$ received by the satellite sensor consists of three parts: atmospheric upward luminance $\mathrm{L} \uparrow$, the energy of the ground's true luminance reaching the satellite sensor after passing through the atmosphere; the atmosphere radiates downward to reflect energy as it reaches the ground.

According to the calculation formula of land surface temperature, this algorithm requires two parameters: atmospheric profile parameters and surface specific emissivity. The processing flow is shown in the following figure1.

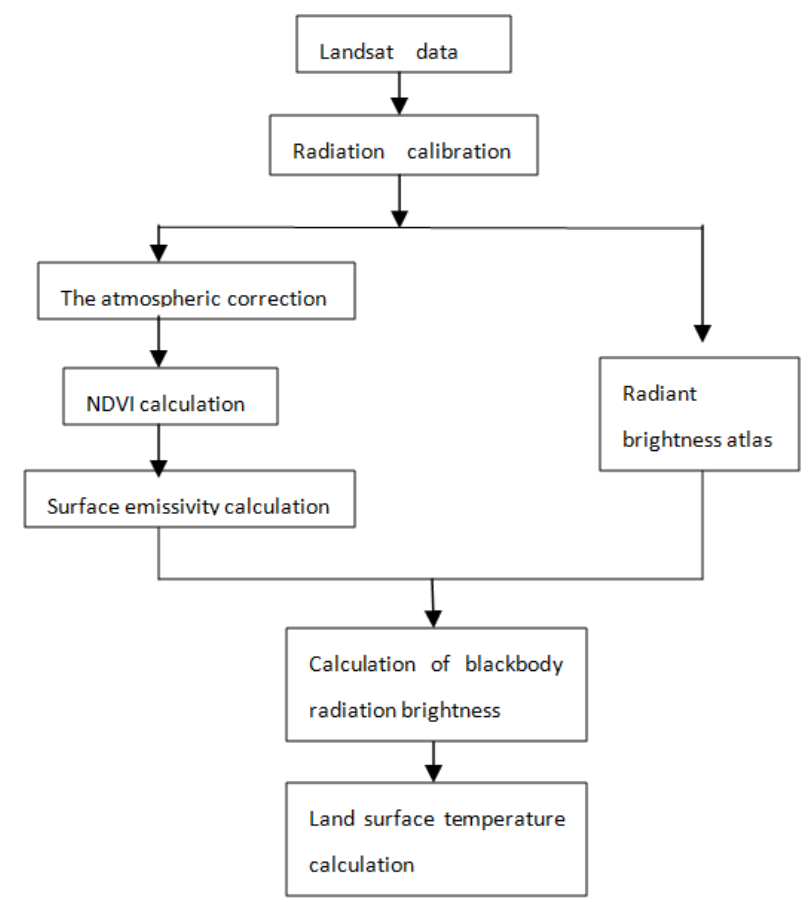

Fig. 1 TIRS inversion flow chart based on atmospheric correction method

\subsection{Calculation of surface specific emissivity}

Specific emissivity is the specific performance of an object's ability to emit electromagnetic waves to the outside world. It is related to the composition, condition and physical properties of surface features.

In this study, the calculation method of surface specific emissivity is the same as that of TM/ETM+6 images. The NDVI threshold method proposed by
Sobrino was used to calculate the surface specific emissivity.

The formula is as follows:

$$
\varepsilon=0.004 P v+0.986
$$

In this formula:

$\mathrm{Pv}$ - the vegetation coverage, which is calculated by the following formula:

$$
P v=\left[\left(N D V I-N D V I_{\text {Soil }}\right) /\left(N D V I_{\text {Veg }}-N D V I_{\text {Soil }}\right]\right.
$$

In this formula:

NDVI - the normalized vegetation index;

$\mathrm{NDVI}_{\text {Soil }}$ - the NDVI value of the completely bare soil or non-vegetation covered area;

NDVI $_{\text {Veg }}$ - The NDVI value of the pixel completely covered by vegetation, namely, the NDVI value of the pure vegetation pixel.

According to the empirical value $\mathrm{NDVI}_{\mathrm{Veg}}=0.70$ and $\mathrm{NDVI}_{\text {Soil }}=0.05$, that is, when the NDVI of a certain pixel is greater than 0.70 , the value of $\mathrm{Pv}$ is 1 , when NDVI is less than $0.05, \mathrm{Pv}$ is 0 .

According to the formula, the vegetation coverage image was calculated. Then calculate the surface specific emissivity.

\section{3 calculation of blackbody radiation brightness and surface temperature}

According to the official website of National Aeronautics and Space Administration(NASA) (http:// atmcorr.gsfc.nasa.gov), inputting the shadow time, center latitude and longitude, and the other corresponding parameters, we can obtain the corresponding parameters: the atmospheric thermal infrared transmittance $\tau$, atmospheric radiation brightness upward $\mathrm{L} \uparrow$ and atmospheric radiation brightness downward $\mathrm{L} \downarrow$.

Then, according to the formula, the black body luminance image at the same temperature can be calculated, and then the surface temperature image with unit of Celsius can be further calculated.

\section{Land surface temperature inversion in BeiBei district of Chongqing}

\subsection{Inversion results}

The inversion results of surface temperature based on the above surface temperature inversion method are shown in the following figure 2 : 

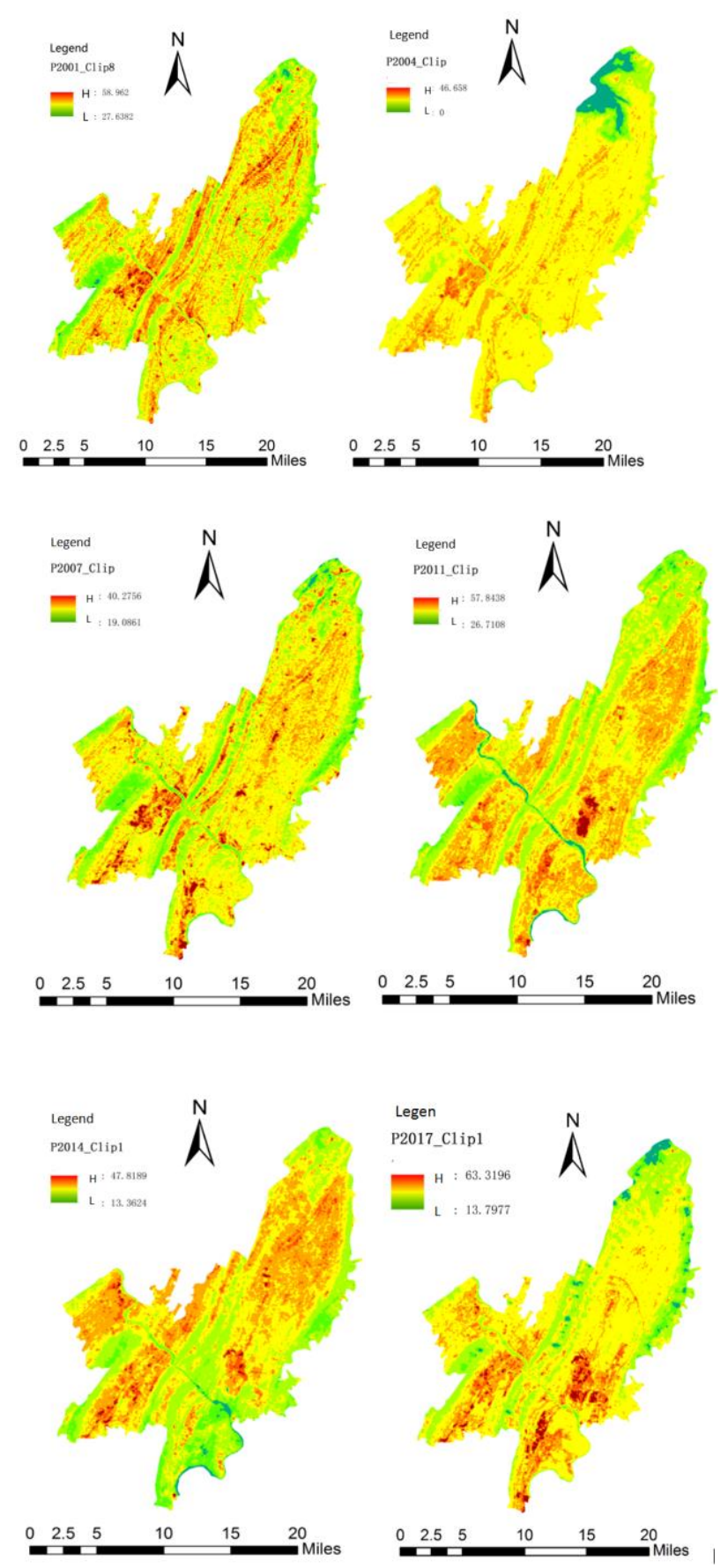

Fig.2 Inversion results of surface temperature in 6 time periods

Through the inversion of land surface temperature by atmospheric correction method, the maximum value, minimum value, mean value and standard deviation of surface temperature in six time phases are calculated. The results are shown in table 1:

Table1 Statistical data of land surface temperature in beibei district in 6 periods $\quad$ (unit: ${ }^{\circ} \mathrm{C}$ )

\begin{tabular}{|c|c|c|c|c|}
\hline $\begin{array}{c}\text { The image of } \\
\text { time }\end{array}$ & $\begin{array}{c}\text { The highest } \\
\text { temperature }\end{array}$ & $\begin{array}{c}\text { The lowest } \\
\text { temperature }\end{array}$ & $\begin{array}{c}\text { The average } \\
\text { temperature }\end{array}$ & $\begin{array}{c}\text { The } \\
\text { standard } \\
\text { deviation }\end{array}$ \\
\hline 2001.07 .17 & 58.96 & 27.64 & 39.26 & 3.50 \\
\hline 2004.07 .25 & 45.66 & 0 & 30.76 & 5.55 \\
\hline
\end{tabular}

\begin{tabular}{|l|l|l|l|l|}
\hline 2007.09 .20 & 40.28 & 19.09 & 25.74 & 1.46 \\
\hline 2011.08 .30 & 57.84 & 26.71 & 38.37 & 3.78 \\
\hline 2014.08 .06 & 47.82 & 13.36 & 32.74 & 3.32 \\
\hline 2017.05 .26 & 63.32 & 13.80 & 38.72 & 3.29 \\
\hline
\end{tabular}

\section{2 result analysis}

In order to more clearly analyze the distribution law of surface temperature in the research area, we used the Robust Statistical method ${ }^{[7]}$ to classify the temperature image, and the formula for calculating the temperature segmentation threshold is as follows:

$$
T=A \pm x \times s d
$$

In this formula:

$\mathrm{T}$ - the calculated temperature threshold;

A - the average surface temperature;

$\mathrm{x}-\mathrm{a}$ multiple of the variance(Values for $0.5,1,1.5$ );

sd - the variance of surface temperature

The temperature threshold calculated according to the formula can be divided into 7 grades such as super high temperature, sub-high temperature and super low temperature (see table 2). According to the grades in table 2, the temperature grade diagram can be obtained.

Table 2 classification of surface temperature

\begin{tabular}{|c|c|c|c|}
\hline $\begin{array}{c}\text { Temperature } \\
\text { threshold }\end{array}$ & $\mathrm{t} \leq-1.5 \mathrm{sd}$ & $-1.5 \mathrm{sd}<\mathrm{t} \leq-1 \mathrm{sd}$ & $-1 \mathrm{sd}<\mathrm{t} \leq-0.5 \mathrm{sd}$ \\
\hline $\begin{array}{c}\text { Temperature } \\
\text { level }\end{array}$ & $\begin{array}{c}\text { Super-low } \\
\text { temperature }\end{array}$ & $\begin{array}{c}\text { Sub-low } \\
\text { temperature }\end{array}$ & $\begin{array}{c}\text { Low } \\
\text { temperature }\end{array}$ \\
\hline
\end{tabular}

\begin{tabular}{|c|c|c|c|c|}
\hline $\begin{array}{c}\text { Temperature } \\
\text { threshold }\end{array}$ & $\begin{array}{c}-0.5 \mathrm{sd} \\
<\mathrm{t} \leq 0.5 \mathrm{sd}\end{array}$ & $0.5 \mathrm{sd}<\mathrm{t} \leq 1 \mathrm{sd}$ & $1 \mathrm{sd}<\mathrm{t} \leq 1.5 \mathrm{sd}$ & $\mathrm{t}>1.5 \mathrm{sd}$ \\
\hline $\begin{array}{c}\text { Temperature } \\
\text { level }\end{array}$ & $\begin{array}{c}\text { Medium } \\
\text { temperature }\end{array}$ & $\begin{array}{c}\text { High } \\
\text { temperature }\end{array}$ & $\begin{array}{c}\text { Sub-high } \\
\text { temperature }\end{array}$ & $\begin{array}{c}\text { Super-high } \\
\text { temperature }\end{array}$ \\
\hline
\end{tabular}

According to the divided surface temperature grade, the area of each temperature grade in the six time phase images is extracted respectively, the temperature area whose temperature is higher than 0.5 times of variance is called High temperature area, and the temperature area whose temperature is lower than -0.5 times of variance is called Llow temperature area, the temperature region between the two is called Medium temperature region, and the corresponding statistical area is shown in table 3:

Table 3 Area statistics of High temperature, Medium temperature and Low temperature areas in BeiBei district (unit: pixel)

\begin{tabular}{|c|c|c|c|}
\hline Year & $\begin{array}{c}\text { High } \\
\text { temperature } \\
\text { area }\end{array}$ & $\begin{array}{c}\text { Medium } \\
\text { temperature area }\end{array}$ & $\begin{array}{c}\text { Low temperature } \\
\text { area }\end{array}$ \\
\hline 2001 & 252391 & 340323 & 244371 \\
\hline 2004 & 142117 & 59712 & 97866 \\
\hline 2007 & 213597 & 401866 & 221622 \\
\hline 2011 & 274031 & 313133 & 249921 \\
\hline
\end{tabular}




\begin{tabular}{|l|l|l|l|}
\hline 2014 & 284327 & 282521 & 270237 \\
\hline 2017 & 183314 & 446831 & 207940 \\
\hline
\end{tabular}

\section{Conclusion}

This paper describes the inversion of land surface temperature and adopts the atmospheric correction method based on the remote sensing data of landsat. Used Landsat5TM and image data Landsat8OLI-TITS. We choose six phases image data during nearly 20 years of BeiBei district in Chongqing. The results showed that from 2004 to 2014, the area of high temperature area increased year by year, and the area of low temperature area also increased year by year, the influencing factors of these changes may be closely related to urbanization construction, population growth and urban greening and so on.

\section{Acknowledgements}

I'd like to thank Chongqing education commission for approving my research project "Image research of urbanization on surface humid and thermal environment-a case study of Chongqing's nine districts", and I would also like to thank Chongqing Real Estate College for providing research fund support for this project, and the last thanks to the efforts of the team members, we believe that our project will get very good results.

Project source: Science and technology research plan of Chongqing education commission in 2018 youth project "Image research on the land surface temperature and humidity environment of urbanization -- a case study of the ninth district of Chongqing" (Project no. : KJQN201805204)

\section{Reference:}

1. Chen Y.Y., Duan S.B., Ren H.Z., et al. Algorithm development for land surface temperature retrieval:Application to Chinese Gaofen-5 data. Remote Sensing, 2017, 9: 161.

2. Fan X.W., Tang B.H., Wu H., et al. A three-channel algorithm for retrieving night-time land surface temperature from MODIS data under thin cirrus clouds. International Journal of Remote Sensing,2015, 36: 4836-4863.

3. Anderson M C, Norman J M, Kustas W P, Houborg R, Starks P J and Agam N. 2008. A thermal-based remote sensing technique for routine mapping of land-surface carbon, water and energy fluxes from field to regional scales. Remote Sensing of Environment, 112(12): 4227-4241 [DOI: 10.1016/j.rse.2008.07.009].

4. Bredehoeft J D, Papadopulos I S. Rates of vertical ground-water movement estimated from the Earth's thermal profile [J]. Water Resources Research, 1965, (2): 325-328.
5. Zeng Y, Huang W, Zhan F B, et al. Study on the urban heat island effects and its relationship with surface biophysical characteristics using MODIS imageries[J]. Geo-spatial Information Science, 2010, 13(1):1-7.

6. Becker, F. The impact of spectral emissivity on the measurement of land surface temperature from a satellite[J]. International Journal of Remote Sensing, 1987, 8(10):1509-1522.

7. Lin J., Chen S.L. ,Surface temperature inversion and thermal environment analysis of xiamen island based on remote sensing [J]. Journal of fujian normal university (natural science edition), 2013,29 (02) : 75-80. 